CONCURSO EDIFICIO FADEU / OCTUBRE - DICIEMBRE 2015

PRIMER LUGAR

Arquitecto responsable

Alberto Moletto

Arquitectos

Alberto Moletto, Sebastián Paredes

Colaboradores

Sebastián Fache, Daniel Castro, Rodrigo Alruiz,

Matías Alarcón

Eficiencia Energética

Antonio Espinoza

Estructuras

Daniel Stagno

(Hoehmann Stagno y Asociados)
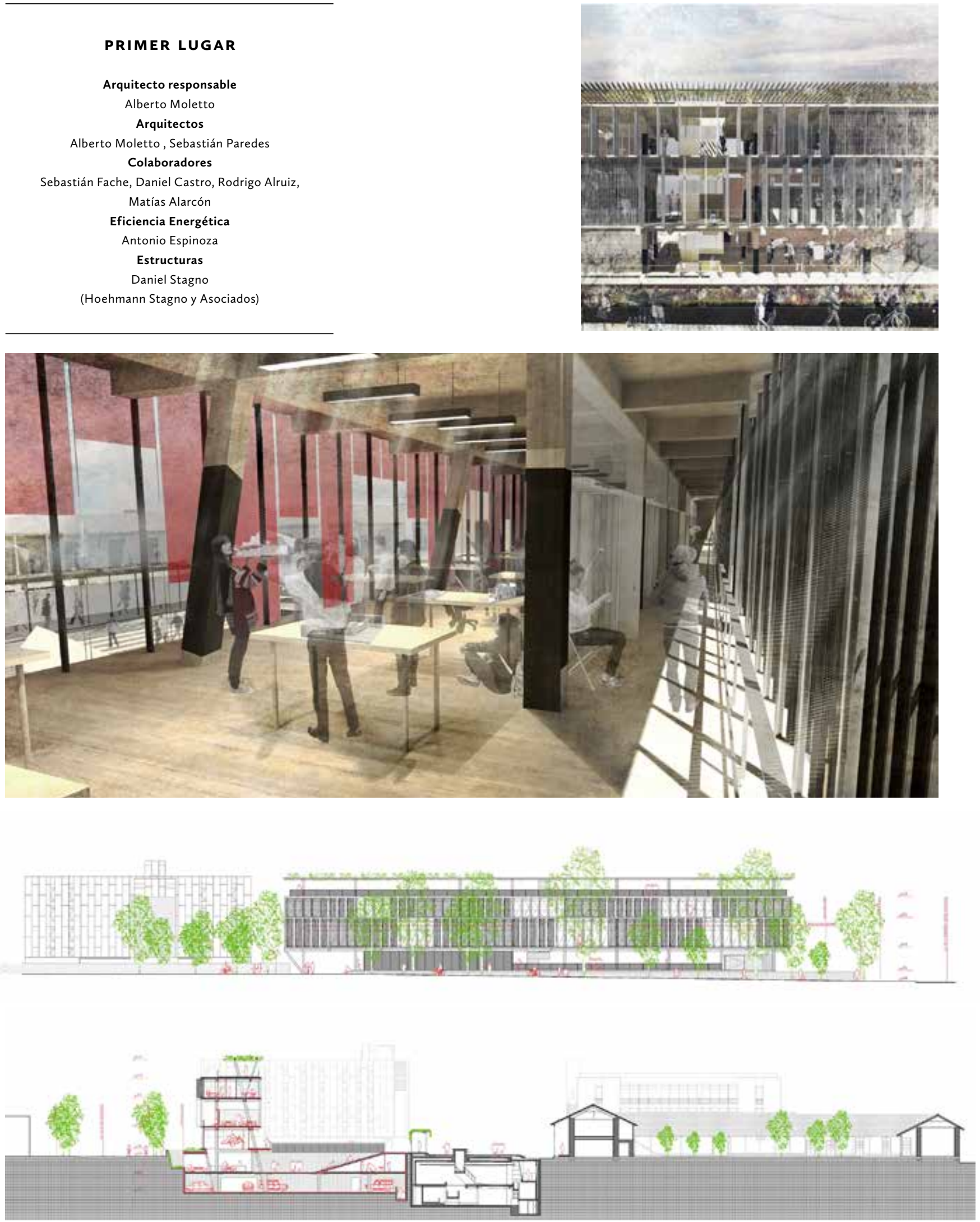
NOTICIAS
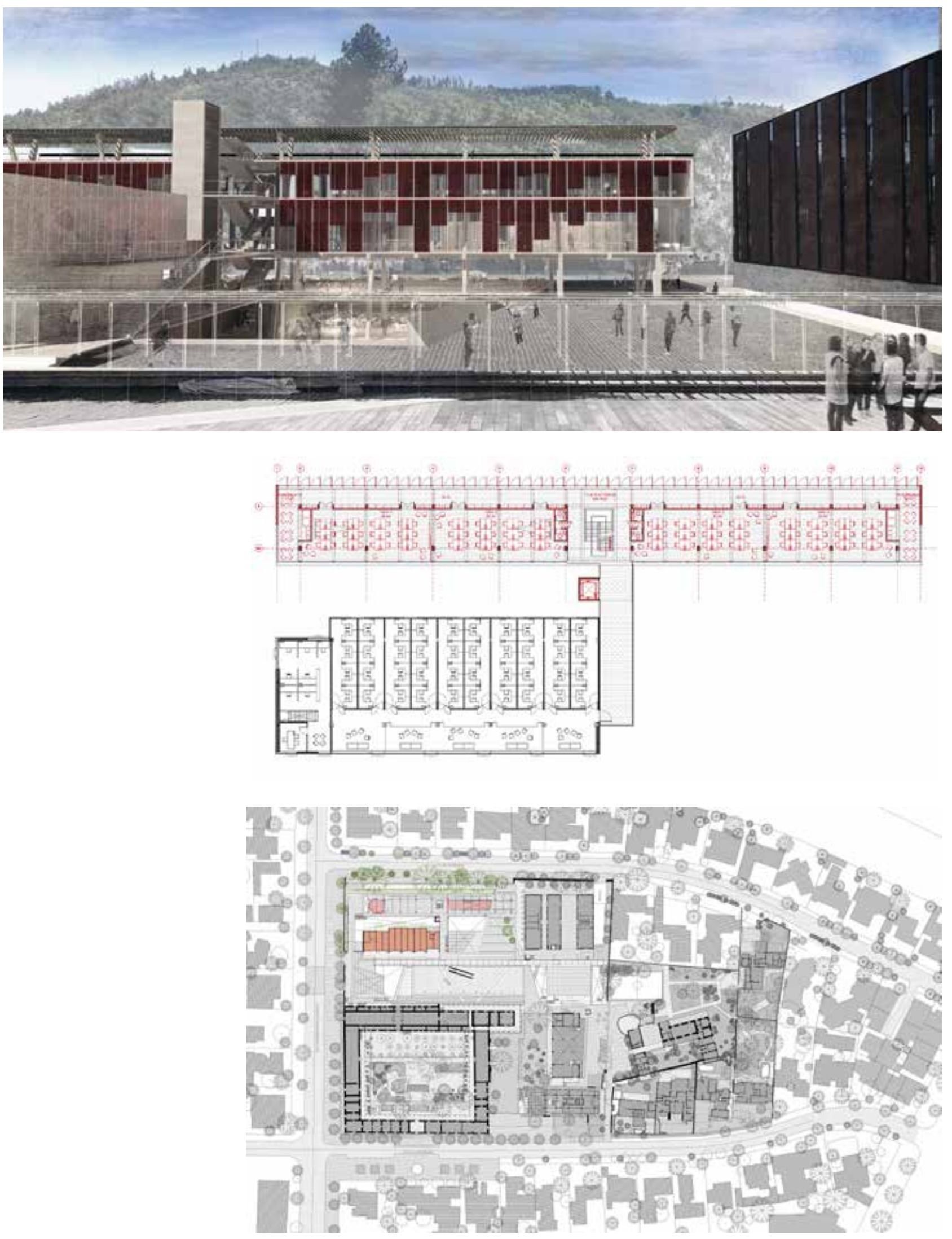


\section{SEGUNDO LUGAR}

Arquitecto responsable

Robert Holmes Lezaeta

Arquitectos

Robert Holmes Lezaeta, María Isabel Harvey Queirolo,

Jonathan Holmes Harvey, Martin Holmes Harvey
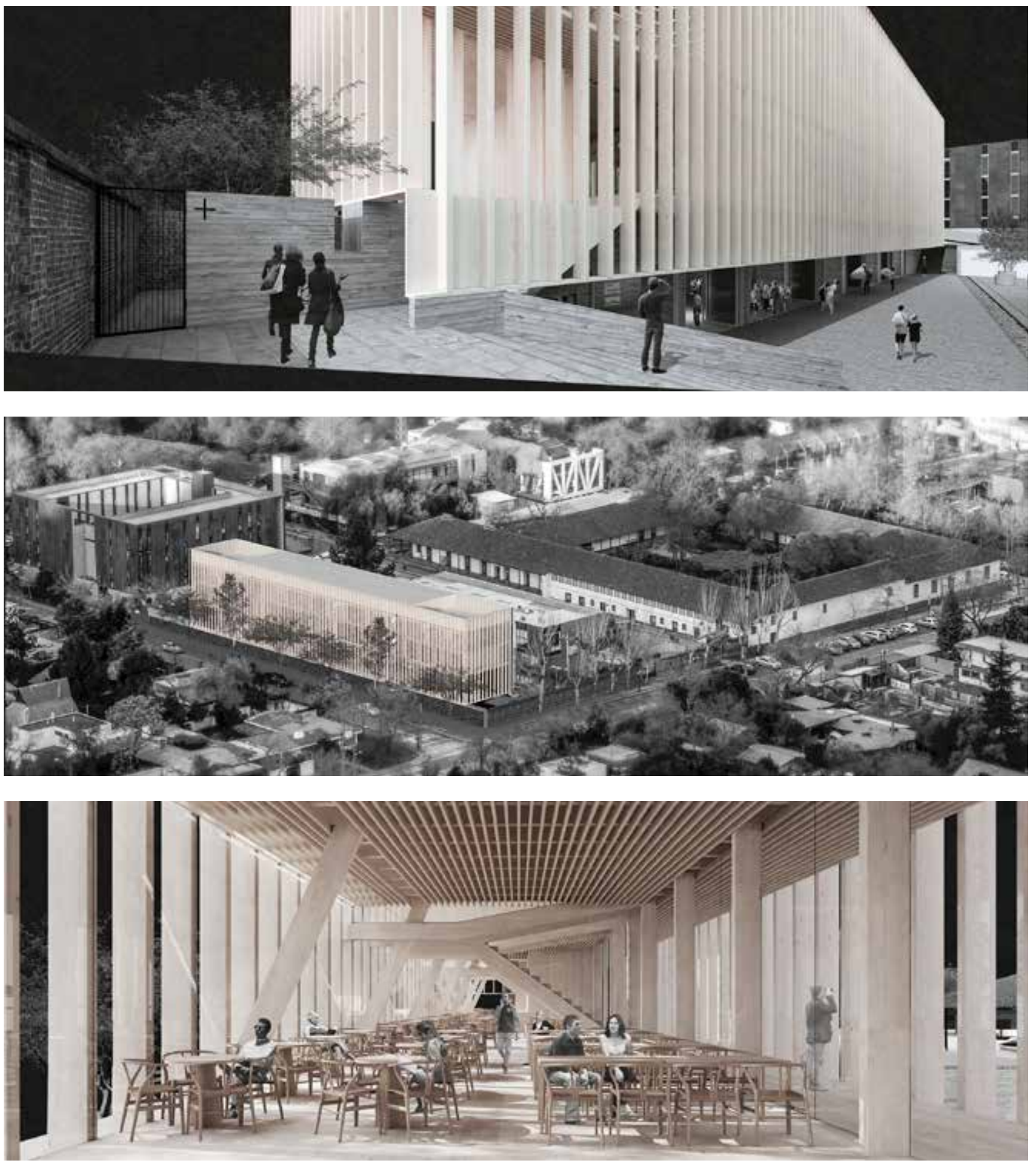
TERCER LUGAR

Arquitecto responsable

Guillermo Hevia García

Arquitectos

Guillermo Hevia García, Nicolás Urzúa Soler,

Pedro González Seguel
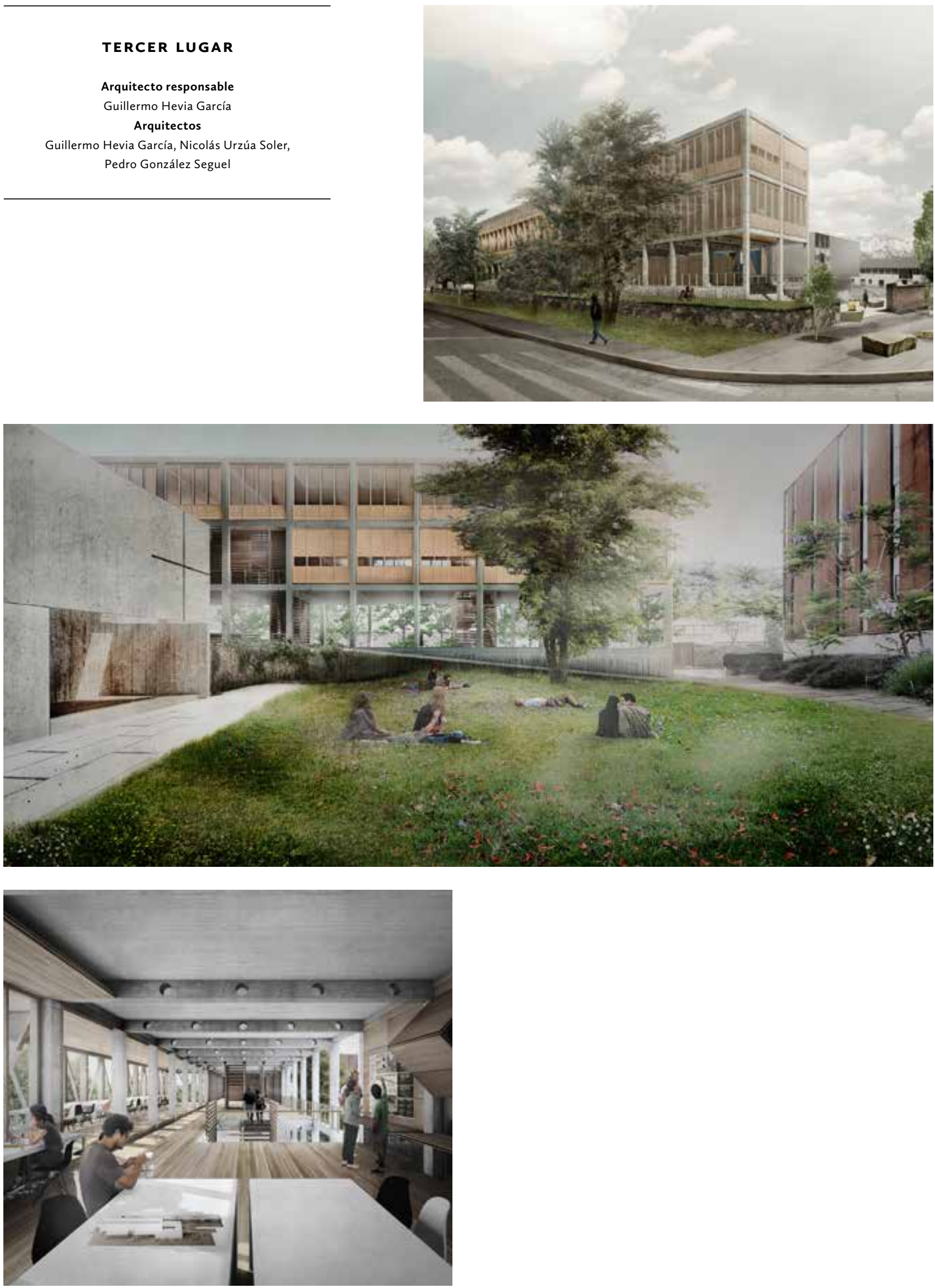


\section{PRIMERA MENCIÓN HONROSA}

Arquitecto responsable

Alejandro Beals

Arquitectos

Alejandro Beals, Loreto Lyon,

Eduardo Carcavilla, Nicolás Lira,

Alessandra Dal Mos, Ada Barbu

\section{SEGUNDA MENCIÓN HONROSA}

Arquitecto responsable

Cristóbal Amunátegui

Arquitectos

Cristóbal Amunátegui, Alejandro Valdés, Mathilde Baietto, Benjamín Gallegos Gabilondo,

Alejandra Pola, Ivana Ivin; Plan Común:

Felipe de Ferrari, Diego Grass,

Thomas Batzenschlager, Oliver Burch
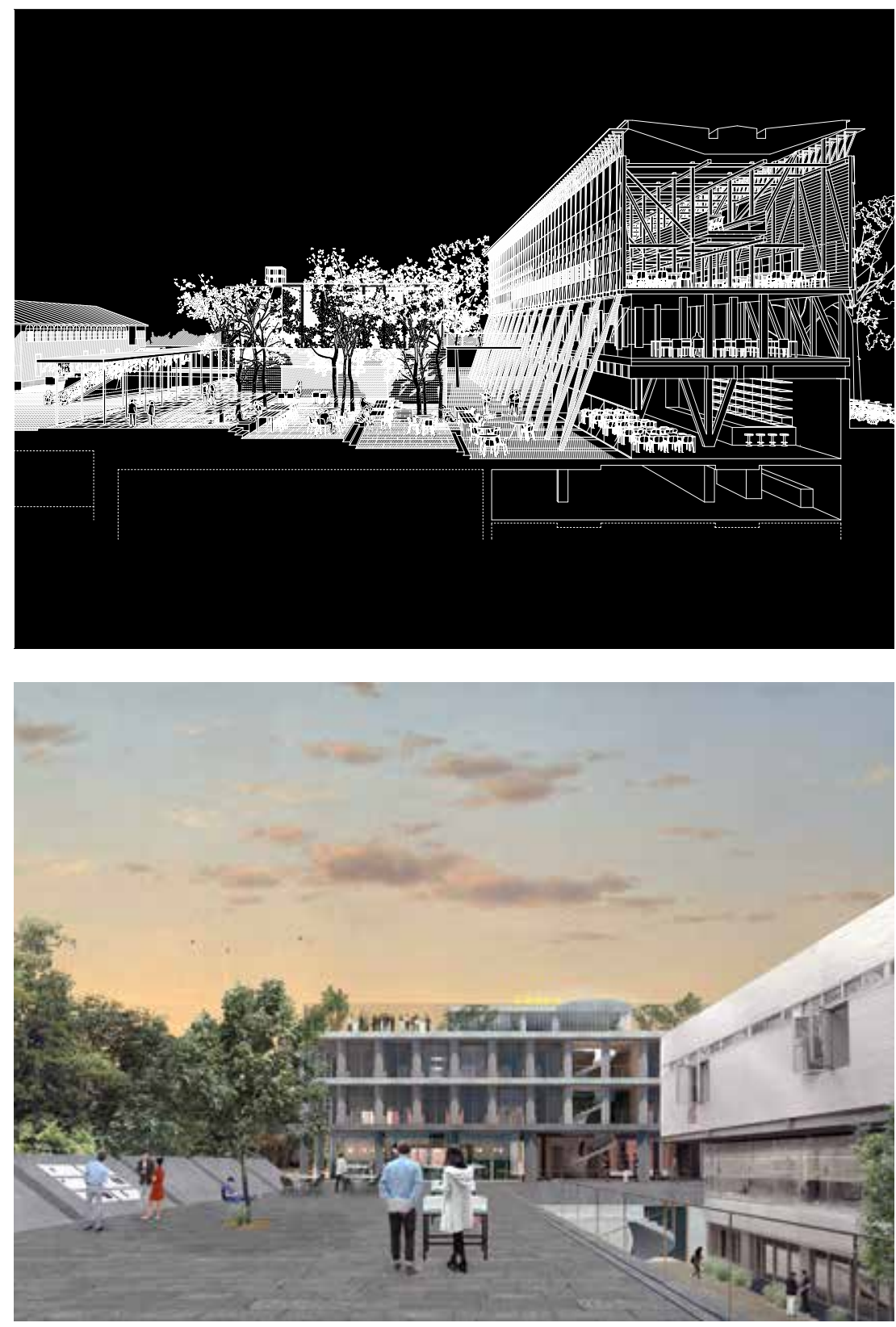

\section{TERCERA MENCIÓN HONROSA}

Arquitecto responsable

Ernesto Silva Raso

Arquitectos

Ernesto Silva Raso, Diego Romero,

Ángela Carvajal, Sebastián López, Rafaela Olivares,

Antonia Leyton, Renzo Mencarini 


\section{ELEFANTES EN LA HABITACIÓN \\ SOBRE EL CONCURSO DEL EDIFICIO \\ FADEU - CMPC}

UMWELT ${ }^{1}$

MARTES O1 DE OCTUBRE DE 2015 - APERTURA DEL CONCURSO Las bases para el nuevo edificio son claras, aunque con una entrega algo exagerada para un anteproyecto y considerando los premios ofrecidos. La entrega consiste en cuatro láminas A1, maqueta 1:200 y una memoria de 2000 palabras. Los premios incluyen tres menciones honrosas (sin retribución monetaria), además de dos, cuatro, y diez millones de pesos para los tres primeros lugares. Como es usual, el primer premio se deduce de los honorarios de los ganadores. Finalmente, todo se corona con una exposición de todas las entregas, un cóctel y, eventualmente, una publicación.

FADEU UC ha sido pionera en generar un modelo de concursos en el cual (a diferencia de los del Estado o de lo que ocurre en otras facultades de la misma Universidad) pueden participar de manera abierta arquitectos jóvenes sin mayor experiencia; sin embargo, si ganan deben asociarse a un arquitecto con la experiencia requerida o bien deben trabajar con la DESE ${ }^{2}$. Esto asegura un contingente amplio y variado de participantes.

\section{MiÉRCOLES 28 de OCTUBRE DE 2015}

Todo se enrarece a un par de semanas de la entrega cuando los medios nacionales informan de un presunto caso de colusión directamente asociado a una de las filiales de la empresa с м Р ${ }^{3}$, quienes como auspiciadores aportan el 50\% de los fondos y la mitad del nombre del edificio. En las bases se indicaba que la empresa pedía mostrar en la entrega cómo se usaría su gama de productos en los distintos espacios de la propuesta, además de contar con un representante -el secretario general de с M PC- dentro de los diez miembros totales del jurado.

No se sabe sobre cómo afectará esto al desarrollo del concurso y todos quedan a la espera de un comunicado oficial sobre el tema. Para todos aquellos dudosos de presentarse al concurso, esto se convierte rápidamente en el elefante en la habitación. ${ }^{4}$

\section{MiÉRCOLES O4 DE NOVIEMBRE DE 2015}

El decano de la Facultad de Arquitectura, Diseño y Estudios Urbanos y el director de la Escuela de Arquitectura participan en un debate en la radio del Centro de Alumnos de la misma Escuela para explicar la situación y responder preguntas. El video fue puesto en línea al día siguiente. ${ }^{5}$

Esta es la única instancia de discusión abierta sobre el tema y tanto el decano como el director concuerdan en que es necesario, al menos, generar un comunicado oficial de la Facultad, pronunciándose y aclarando su posición frente al problema. Hasta donde pudimos averiguar no hubo tal comunicado. Tampoco hubo reclamos colectivos por parte de los participantes inscritos ${ }^{6}$, el gremio $^{7}$ o los arquitectos en general, agrupados o individualmente, al menos de manera pública y oficial.
MIÉRCOLES O9 DE DICIEMBRE DE 2015 - DÍA DE ENTREGA DE LOS ANTEPROYECTOS

Al concurso anterior de la Escuela de Arquitectura -realizado dos años antes para un edificio con condiciones y premios similares- se presentaron 54 proyectos. En este caso, 60 personas compraron las bases y finalmente se recibieron 42 propuestas.

VIERNES 18 de DICIEMBRE DE 2015 - díA DE LA PREMIACIÓN Los seis premiados están dentro de la categoría sub-40, dejando fuera del podio a reconocidos arquitectos de generaciones ya consolidadas y con mayor experiencia.

\section{P. D.: EL FUTURO}

En medio de la contingencia y sobre todo en el contexto de la Facultad de Arquitectura, Diseño y Estudios Urbanos, esta era una oportunidad para demostrar que hay cosas que no se deben dejar pasar o que al menos debemos afrontar de manera colectiva y frontal.

Tarde o temprano los arquitectos tendremos que discutir acerca de las condiciones que nos imponen y a su vez las que nosotros imponemos, más allá de nuestra desenfrenada necesidad de competir, ganar y construir.

He aquí el segundo y mucho más grande elefante dentro de la habitación.

I El texto está escrito desde la posición de una oficina que decidió no participar en el concurso.

2 La Dirección de Extensión y Servicios Externos (DESE) ofrece los servicios profesionales de la FADEU a entidades públicas y privadas con estrategias de gestión basadas en una estructura docente y una red académica altamente capacitadas.

3 La colusión se asocia específicamente a CM PC Tissue, parte del holding С M PC que también incluye a c M PC Maderas, rama de la que se pedía utilizar una serie de productos en el proyecto. Los primeros artículos en la prensa datan del 28 de octubre de 2015 .

4 Expresión metafórica que hace referencia a una verdad o hecho evidente que es ignorado de manera consciente o que pasa inadvertido. La presencia de un elefante en una habitación, un hecho imposible de evadir, es deliberadamente ignorado por las personas que han optado por no hacerse cargo del problema que esta realidad implica. La expresión también se aplica a un problema o riesgo obvio que nadie quiere o que nadie está dispuesto a discutir. Cambridge academic content dictionary. (Cambridge: Cambridge University Press, 2009), 298.

5 Para escuchar la entrevista completa ver: http://www.ustream.tv/ recoded/7699367I

6 Solamente hubo dos preguntas en la web y estas fueron respondidas de manera escueta a través de http://concursolocontador.com/consultas/.

7 El concurso fue auspiciado hasta el final por el Colegio de Arquitectos de Chile.

\begin{abstract}
UMWELT
<info@umw.cl>

Oficina de investigación y práctica en Arquitectura y Diseño Territorial, fundada en Santiago de Chile a principios del 2ori por Ignacio García Partarrieu y Arturo Scheidegger, ambos Arquitectos y Magíster en Arquitectura de la Pontificia Universidad Católica de Chile. Ambos son profesores de la Universidad Católica y la Universidad Mayor. Sus obras y proyectos han sido expuestos en la Bienal de Shenzhen y Hong Kong, la Bienal de Venecia, la Bienal de Santiago o la galería Storefront for Art and Architecture de Nueva York. También han dictado charlas y conferencias en Chile, Canadá, Suiza y Alemania. Han sido premiados en distintas instancias y concursos, entre ellos el primer lugar en el concurso del Memorial PP 29 y del yap Constructo 2014.
\end{abstract}

